\title{
Stage II Lung Cancer AJCC v6
}

National Cancer Institute

\section{Source}

National Cancer Institute. Stage II Lung Cancer AJCC v6. NCI Thesaurus. Code C8954.

Stage II includes: IIA (T1, N1, M0) and IIB (T2, N1, M0) or (T3, N0, M0). T1: Tumor is 3 $\mathrm{cm}$ or less in greatest dimension, surrounded by lung or visceral pleura, and without bronchoscopic evidence of invasion more proximal than the lobar bronchus. T2: Tumor has any of the following features of size or extent: more than $3 \mathrm{~cm}$ in greatest dimension; involves the main bronchus, $2 \mathrm{~cm}$ or more distal to the carina; invades the visceral pleura; associated with atelectasis or obstructive pneumonitis that extends to the hilar region but does not involve the entire lung. T3: Tumor (of any size) directly invades any of the following: chest wall (including superior sulcus tumors), diaphragm, mediastinal pleura, parietal pericardium; or tumor in the main bronchus less than $2 \mathrm{~cm}$ distal to the carina but without involvement of the carina; or associated atelectasis or obstructive pneumonitis of the entire lung. N0: No regional lymph node metastasis. N1: Metastasis to ipsilateral peribronchial and/or ipsilateral hilar lymph nodes, and intrapulmonary nodes including involvement by direct extension of the primary tumor. MO: No distant metastasis. (AJCC 6th ed.) 